\title{
Inhibition of hypoxic pulmonary vasoconstriction in isolated rat resistance arteries by atrial natriuretic peptide
}

\author{
T.K. Rogers, J.S. Thompson, A.H. Morice
}

\begin{abstract}
Inhibition of hypoxic pulmonary vasoconstriction in isolated rat resistance arteries by atrial natriuretic peptide. T.K. Rogers, J.S. Thompson, A.H. Morice. @ERS Journals Ltd 1997.

ABSTRACT: Atrial natriuretic peptide (ANP) is a vasodilator secreted by the heart in response to right atrial stretch. We have hypothesized that ANP may be released to attenuate pulmonary hypertension due to hypoxia. We have examined whether ANP inhibits hypoxic pulmonary vasoconstriction (HPV) in isolated pulmonary resistance vessels (PRV) from chronically hypoxic (CH) rats, compared to airbreathing, control $(C)$ rats.

After at least 17 days of chronic hypoxia, vessels $(n=29)$ were dissected from $\mathbf{C H}$ and $C$ littermates and mounted in an automated myograph. The inhibitory effect of ANP on the rapid first contractile phase of HPV, and the relaxant effect of ANP on vessels tonically contracted in the second phase of HPV, were studied.

ANP caused concentration-dependent inhibition of HPV in both $\mathrm{C}$ and $\mathrm{CH}$ vessels $(\mathbf{p}<0.001)$, whilst vehicle had no effect (mean maximum inhibition was 88 and $101 \%$, respectively, at $17 \mathrm{nM}$ ANP). ANP also caused significant concentrationdependent relaxation of the second contractile phase of HPV, which was similar in $\mathrm{C}$ and $\mathrm{CH}$ vessels (mean maximum relaxation of 89 and $94 \%$, respectively; median effective concentrations were 2.4 and $2.0 \mathrm{nM}$, respectively).

We conclude that atrial natriuretic peptide is a potent antagonist of both contractile phases of hypoxic pulmonary vasoconstriction in isolated rat pulmonary resistance vessels at concentrations similar to those observed in hypoxic pulmonary hypertension in life. There was no difference between vessels from chronically hypoxic and control animals.
\end{abstract}

Eur Respir J 1997; 10: 2061-2065.
Pulmonary Medicine, Dept of Medicine, University of Sheffield, Sorby 3, Northern General Hospital, Sheffield, UK

Correspondence: A.H. Morice

Pulmonary Medicine

Dept of Medicine

The University of Sheffield

Sorby 3

Northern General Hospital

Herries Road

Sheffield S5 7AU

UK

Keywords: Atrial natriuretic peptide, chronic hypoxia, hypoxic pulmonary vasoconstriction, myograph, natriuretic peptides, pulmonary hypertension

Received: December 41996

Accepted July 41997

This work was supported by a fellowship from Bristol-Myers Squibb Pharmaceuticals Ltd (TKR). JST was funded by The Special Trustees for the Former United Sheffield Hospitals.
We have hypothesized that the cardiac hormone, atrial natriuretic peptide (ANP), may be released to attenuate pulmonary hypertension due to hypoxia. We have examined whether ANP inhibits hypoxic pulmonary vasoconstriction (HPV) in isolated pulmonary resistance vessels.

ANP is a vasodilator of the pulmonary vasculature hypothesized to have a physiological role in modulating pulmonary vascular resistance. Release of ANP is governed by right atrial stretch and because of its short half-life, intravascular concentrations are highest in the pulmonary circulation. ANP is elevated in conditions characterized by pulmonary hypertension. Levels are modestly increased in chronic obstructive pulmonary disease (COPD) and more markedly in severe pulmonary hypertension [1-4]. In patients with COPD we have demonstrated that infusion of ANP leads to a fall in mean pulmonary artery pressure, pulmonary artery wedge pressure and total pulmonary vascular resistance, without significant effects on the systemic vasculature [4].

The normal pulmonary vasculature has low intrinsic tone and to demonstrate the vasodilator properties of ANP precontraction is required. In the isolated lung and in isolated vessels, ANP has been shown to cause vasodilatation when tone is increased by pharmacologi- cal means [5-10]. The most important physiological vasoconstrictor of the pulmonary circulation is hypoxia and the effect of ANP on hypoxic pulmonary vasoconstriction (HPV) has been studied in anaesthetized animals $[6,11,12]$ and using isolated lung preparations [10]. Until recently, it had proved difficult to demonstrate consistent HPV in isolated pulmonary arteries. We and others have developed a technique which allows the study of HPV in isolated resistance arteries by priming with prostaglandin $\mathrm{F}_{2 \alpha}[13,14]$. In this system, HPV is biphasic, consisting of a rapid, endothelially independent first phase and a slowly developing second phase, which is endothelially dependent. We have now examined the effect of ANP on both phases of HPV in isolated vessels. Chronic hypoxia causes pulmonary hypertension in both humans and animal models, which is associated with muscular remodelling of pulmonary arteries and arterioles. In a previous study, we examined the effect of chronic hypoxia on the relaxant response to ANP in prostaglandin $\mathrm{F}_{2 \alpha}$-precontracted pulmonary resistance vessels [9]. ANP caused a greater relaxation in vessels from chronically hypoxic animals, and in this present study we have used similar experimental conditions to determine whether this is also true of HPV. 


\section{Materials and methods}

\section{Animals}

Male Wistar rats $(n=29)$, supplied by the University of Sheffield Field Laboratories, were used. Animals were 5 weeks old at the start of the experiments.

\section{Study design}

Littermate rats were divided at 5 weeks of age, when half were placed in a normobaric hypoxic chamber and half were designated as normoxic control (C) animals and were housed in the same room, breathing room air. Animals were placed in the hypoxic chamber in order to model the development of pulmonary hypertension. Chronic hypoxia $(\mathrm{CH})$ was achieved by maintaining the internal environment at $10 \% \mathrm{O}_{2}$ and all rats were allowed food and water ad libitum. After at least 17 days (mean 30 days) littermate $\mathrm{C}$ and $\mathrm{CH}$ pairs were studied.

\section{Methods}

Vessel dissection and mounting. Animals were anaesthetized with intraperitoneal pentobarbitone $\left(60 \mathrm{mg} \cdot \mathrm{kg}^{-1}\right)$ and heart and lungs were removed en bloc. Further dissection and mounting of small pulmonary arteries onto an automated microvascular myograph (Cambustion Ltd, Cambridge, UK) was performed using an operating microscope as described previously [9]. Vessels were studied as ring preparations at a resting tension equivalent to a transmural pressure of $4.7 \mathrm{kPa}(35 \mathrm{mmHg})$. The organ bath contained physiological salt solution (PSS) maintained at $37^{\circ} \mathrm{C}$ and bubbled with $95 \% \mathrm{O}_{2} / 5 \%$ $\mathrm{CO}_{2} . \mathrm{C}$ and $\mathrm{CH}$ vessel pairs were mounted in each of the two organ baths of the multichannel myograph. After an initial equilibration period of approximately $1 \mathrm{~h}$, vessel viability and contractile reproducibility were assessed by triplicate contractions to a maximal depolarizing concentration of $\mathrm{KCl}(100 \mathrm{mM})$. Any vessel that did not actively contract by greater than $0.5 \mathrm{mN} \cdot \mathrm{mm}^{-1}$ was assumed to be damaged and was discarded.

Hypoxic contractions. Vessels were precontracted with prostaglandin $\mathrm{F}(\mathrm{PGF})_{2 \alpha}(10 \mu \mathrm{M})$, and the response to hypoxia measured after steady-state tension was achieved. The induction of basal tone with vasoactive agents has previously been demonstrated to greatly enhance HPV $[13,14]$ in rat isolated pulmonary arteries. PGF ${ }_{2 \alpha}$ was used because it produces a sustained and more reproducible precontraction than other agents (e.g. $\mathrm{KCl}$, angiotensin II). To produce hypoxic conditions, the PSS in the organ bath was perfused with $5 \% \mathrm{CO}_{2} / 95 \% \mathrm{~N}_{2}$. With the bath uncovered and exposed to room air, this produced a resting partial pressure of oxygen in arterial blood $\left(\mathrm{Pa}, \mathrm{O}_{2}\right)$ within the PSS of $10-12 \mathrm{kPa}$. When the organ bath was covered, the $P \mathrm{a}, \mathrm{O}_{2}$ decreased to $2-3 \mathrm{kPa}$ (Corning blood gas analyser, Corning Halstead, Essex, UK; and Strathkelvin Instruments oxygen meter model 781 Bearsdon, Glasgow, UK). Perfusion was maintain-

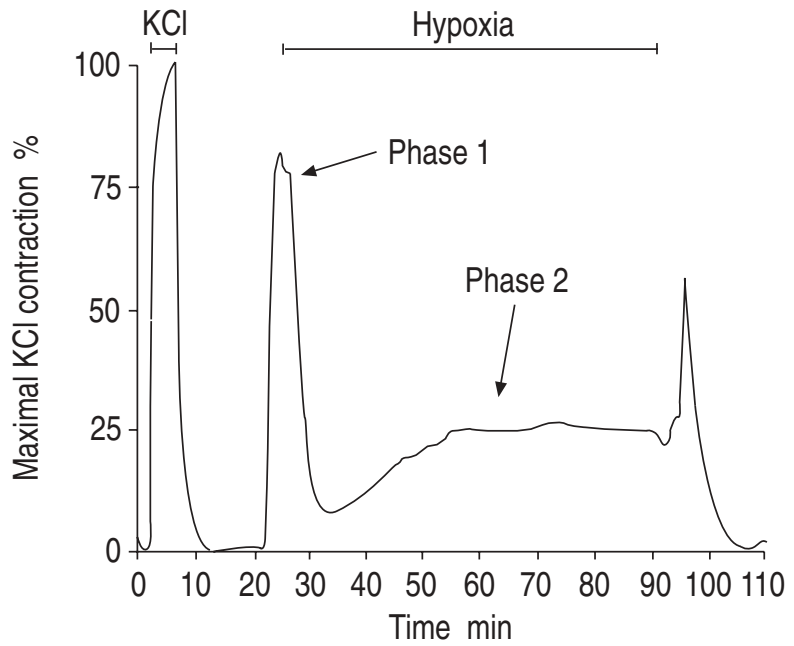

Fig. 1. - A typical contraction of a control pulmonary resistance vessel (diameter $232 \mu \mathrm{m}$ ) in response to hypoxia, expressed as percentage of a maximum $\mathrm{KCl}$ contraction. The organ bath was initially open to room air, being bubbled with $95 \% \quad \mathrm{~N}_{2} / 5 \% \quad \mathrm{CO}_{2}$. A contraction in response to $\mathrm{KCl}(100 \mathrm{mM})$ was performed and the bath washed four times with physiological salt solution (PSS). Tone was produced in the vessel with $\mathrm{PDG}_{2 \alpha}(10 \mu \mathrm{M})$, and when this contraction had stabilized, the bath was covered, causing the partial pressure of oxygen of the PSS to fall. The biphasic nature of the hypoxic contraction is demonstrated. The lid was removed after $95 \mathrm{~min}$.

ed until a maximum contractile response was seen, generally within 2-5 min (first contractile phase). After 30 min, a second contractile peak was observed (fig. 1). Hypoxic responses were reported as maximum active tension generated above baseline during the first and second contractile phases of hypoxia.

Experiment 1: inhibition of first phase of hypoxic vasoconstriction by ANP

After stabilization of the precontraction to $\mathrm{PGF}_{2 \alpha}(10$ $\mu \mathrm{M}), \mathrm{C}$ and $\mathrm{CH}$ vessel pairs were exposed to hypoxia. When the first contractile phase of the hypoxic response reached a plateau, the baths were opened, resulting in rapid relaxation to the $\mathrm{PGF}_{2 \alpha}$ baseline, and the bath was washed four times with oxygenated PSS. Four such challenges were performed to establish a baseline, before subsequent hypoxic challenges in the presence of incremental doses of ANP (17 pM to $60 \mathrm{nM}$ ) or ANP vehicle (as negative control).

Experiment 2: the effect of ANP on the second phase of $H P V$

Different $\mathrm{C}$ and $\mathrm{CH}$ vessels were used in this study. Cumulative doses of ANP (0.017-17 nM) were added when the second contractile phase of HPV had plateaued, after about $1 \mathrm{~h}$ of continuous bubbling with the hypoxic gas mixture.

\section{Solutions and drugs}

PSS consisted of $\mathrm{NaCl}(120 \mathrm{mM}), \mathrm{KCl}(4.7 \mathrm{mM})$, $\mathrm{CaCl}_{2} \cdot 2 \mathrm{H}_{2} \mathrm{O}(2.5 \mathrm{mM}), \mathrm{MgSO}_{4} \cdot 7 \mathrm{H}_{2} \mathrm{O}(1.17 \mathrm{mM}), \mathrm{NaHCO}_{3}$ 
(25 mM), $\mathrm{KH}_{2} \mathrm{PO}_{4}(1.18 \mathrm{mM})$, ethylenediamine tetraacetic acid (EDTA) $(26.9 \mu \mathrm{M})$, and glucose $(5.5 \mathrm{mM})$ dissolved in de-ionized water. This was continuously bubbled with $95 \% \mathrm{O}_{2}, 5 \% \mathrm{CO}_{2}$ mixture, maintaining a $\mathrm{pH}$ of approximately 7.4. PGF $_{2 \alpha}$ (Sigma, Poole, Dorset, UK) was dissolved in normal saline. Human ANP (Sigma) was dissolved in a solvent of 50\% (w/v) Haemaccel (Hoechst, Hanslow, Middlesex, UK) and 50\% normal saline (150 $\mathrm{mM}$ ), at $\mathrm{pH} 4$, by adding drops of $1 \%$ acetic acid, to make a stock solution of $100 \mu \mathrm{g} \cdot \mathrm{mL}^{-1}$. Subsequent dilutions were made with normal saline. This procedure was followed to minimize adsorption of ANP onto plastic containers and pipette tips.

\section{Statistical analysis}

Parametric data were analysed using analysis of variance (ANOVA) or student's t-tests, as appropriate. Median effective concentrations (EC50s) did not follow a normal distribution and the Wilcoxon signed rank test was used. A p-value of less than 0.05 was considered significant. Values were reported as mean \pm SEM, except where stated. The tension data for individual vessels was recorded digitally. The data for hypoxic responses of the various groups of vessels were averaged, after ensuring that the peak of the first phase of contraction coincided for all the vessels in the group.

\section{Results}

$\mathrm{CH}$ animals weighed significantly $(\mathrm{p}<0.001)$ less than their littermate controls $(247 \pm 10$ and $287 \pm 12$ g, respectively), and the vessels from both groups were of similar diameter $(278 \pm 58$ and $245 \pm 54 \mu \mathrm{m}$, respectively, table $1)$.

When the organ baths were exposed to atmospheric air, the mean $(\mathrm{SD})$ partial pressure of oxygen $\left(\mathrm{PO}_{2}\right)$ was $10.9 \pm 2.3 \mathrm{kPa}$, partial pressure of carbon dioxide $\left(\mathrm{PCO}_{2}\right)$ was $3.7 \pm 0.5 \mathrm{kPa}$, pH $7.45 \pm 0.07(\mathrm{n}=6)$. Under these conditions, the maximum $\mathrm{KCl}$ responses were significantly lower in $\mathrm{CH}$ vessels; $2.3 \pm 0.2$ compared with $3.8 \pm$ $0.9 \mathrm{mN} \cdot \mathrm{mm}^{-1}$ in $\mathrm{C}$ vessels.

Approximately $5 \mathrm{~min}$ after the organ baths were sealed, the vessels generated a rapid "phase 1" vasoconstriction (fig. 1). The threshold gas tensions for first-phase HPV were $P_{\mathrm{O}_{2}} 5.5 \pm 1.7 \mathrm{kPa}, \mathrm{PCO}_{2} 4.4 \pm 0.7 \mathrm{kPa}, \mathrm{pH} 7.42 \pm 0.10$ $(n=20)$. Vasoconstriction was significantly greater in $C$

Table 1. - Mass of rats, and internal diameter and contractility of pulmonary resistance vessels from control rats of chronically hypoxic rats

\begin{tabular}{llcr}
\hline & $\begin{array}{c}\text { Control } \\
\text { vessel } \\
(\mathrm{n}=10)\end{array}$ & $\begin{array}{c}\text { Chronically } \\
\text { hypoxic } \\
\text { vessels } \\
(\mathrm{n}=10)\end{array}$ & $\begin{array}{c}\text { ANP } \\
\text { vehicle } \\
\text { control } \\
(\mathrm{n}=9)\end{array}$ \\
\hline Animal mass g & $287(12)$ & $247(10)$ & $282(10)$ \\
Vessel diameter $\mu \mathrm{m}$ & $252(55)$ & $278(58)$ & $245(54)$ \\
KClmax mN.mm & $3.8(0.9)$ & $2.3(0.2)$ & $4.1(0.9)$ \\
Mean HPV mN.mm ${ }^{-1}$ & $3.5(1.2)$ & $1.8(0.2)$ & $3.4(0.9)$ \\
\hline
\end{tabular}

Results are mean ( \pm SEM). KClmax: maximum mean contractile response to $\mathrm{KCl}(100 \mathrm{mM})$; HPV: maximum first contractile phase of hypoxic pulmonary vasoconstriction. than $\mathrm{CH}$ vessels. Active tension was $3.55 \pm 1.24 \mathrm{mN} \cdot \mathrm{mm}^{-1}$ in $\mathrm{C}$ vessels and $1.94 \pm 0.19 \mathrm{mN} \cdot \mathrm{mm}^{-1}$ in $\mathrm{CH}$ vessels $(\mathrm{p}<0.05)$. If expressed as a percentage of maximum $\mathrm{KCl}$ contractions, however, these responses were similar at 82 and $88 \%$, respectively.

The first contractile phase spontaneously reduced after about $5 \mathrm{~min}$ and was succeeded by a sustained, second phase of vasoconstriction ("phase 2"), which reached a plateau approximately $40 \mathrm{~min}$ after the peak of phase 1 (fig. 1). The gas tensions during peak second phase contraction were $P_{\mathrm{O}_{2}} 2.1 \pm 0.9 \mathrm{kPa}, \mathrm{PCO}_{2} 6.7 \pm 0.6$ $\mathrm{kPa}$ and $\mathrm{pH} 7.17 \pm 0.04$. This second phase of vasoconstriction produced similar increases in active tension in $\mathrm{C}$ and $\mathrm{CH}$ vessels, $1.1 \pm 0.22$ and $1.16 \pm 0.21 \mathrm{mN} \cdot \mathrm{mm}^{-1}$, respectively. Both phases of contraction were rapidly and completely reversible by re-oxygenation.

\section{Experiment 1: effect of ANP on phase 1 of the hypoxic response}

The first phase of the hypoxic response was significantly (ANOVA, $\mathrm{p}<0.001)$ inhibited by ANP $(17 \mathrm{nM})$ in both $\mathrm{C}$ and $\mathrm{CH}$ vessels, whilst ANP vehicle alone

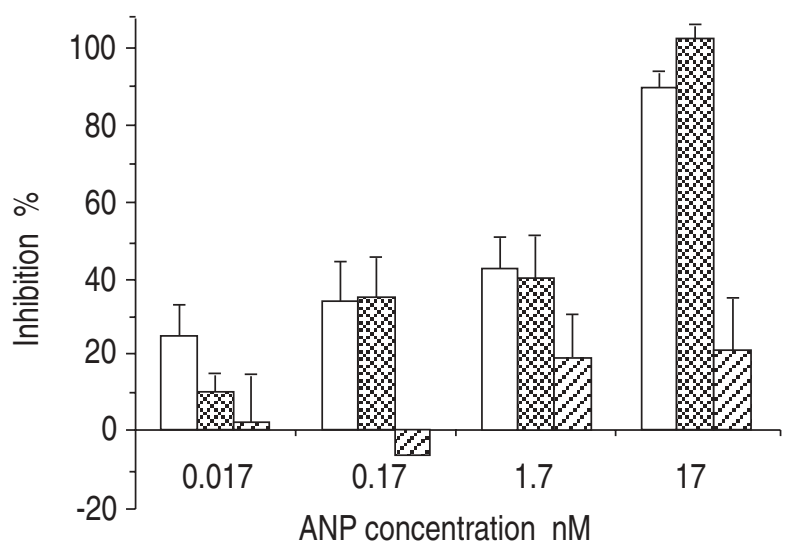

Fig. 2. - The mean \pm SEM percentage inhibition of phase 1 of the hypoxic contractile responses to control and chronically hypoxic pulmonary resistance vessels by atrial natriuretic peptide (ANP) (17 pM-17 nM). $\square$ : control vessels $(\mathrm{n}=10) ; \square$ : chronically hypoxic vessels ( $\mathrm{n}=10) ; \square$ : ANP vehicle control $(\mathrm{n}=9)$.

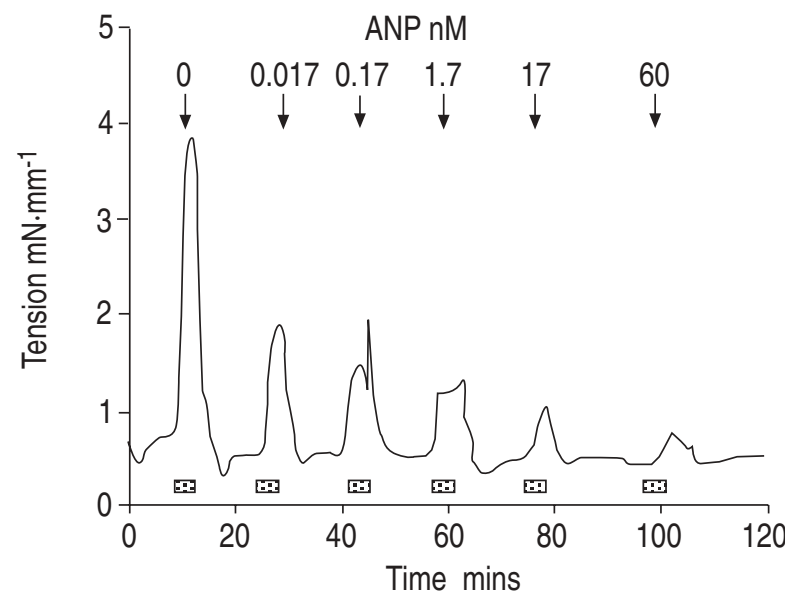

Fig. 3. - Typical trace showing phase 1 contractile hypoxic responses of a control pulmonary resistance vessel, internal diameter 266 $\mu \mathrm{m}$, in the presence of increasing concentrations of atrial natriuretic peptide (ANP) (17 pM-60 nM). Shaded areas represent periods of hypoxia. 


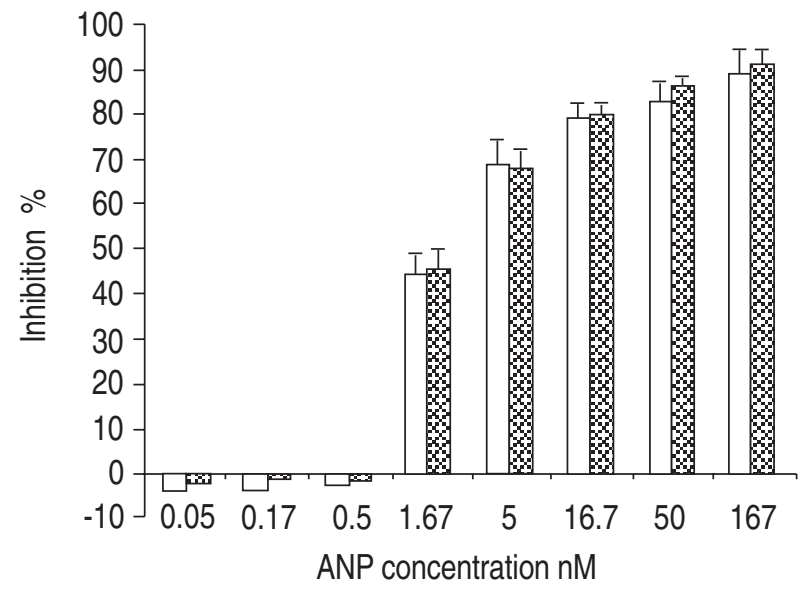

Fig. 4. - The spasmolytic effect of atrial natriuretic peptide (ANP) $(0.17-288 \mathrm{nM})$ on stable, phase 2 contractile hypoxic response of control $(\square)$ and chronically hypoxic $(\square)$ pulmonary resistance vessels. $n=10$ vessels in each group.

caused no significant change in contractility (ANOVA, $\mathrm{p}=0.4$ ) (fig. 2). A typical trace is shown for a $\mathrm{C}$ vessel (internal diameter $266 \mu \mathrm{m}$ ) in figure 3 . There were no significant differences between the effects of ANP at any concentration on the $\mathrm{C}$ and $\mathrm{CH}$ vessels.

\section{Experiment 2: effect of ANP on phase 2 of the hypoxic response}

There was dose-dependent relaxation of the vessels tonically contracted by hypoxia. Peak relaxation was similar at 89 and $94 \%$ in $\mathrm{C}$ and $\mathrm{CH}$ vessels, respectively (fig. 4). The EC50 was also similar, with values of 2.4 and $2.0 \mathrm{nM}$ in $\mathrm{C}$ and $\mathrm{CH}$ vessels, respectively $(\mathrm{p}=0.87)$.

\section{Discussion}

In this series of experiments we looked at the effect of a putative homeostatic hormone, ANP, on the main physiological mediator of pulmonary vascular resistance, namely HPV. HPV arose early in evolution and is present in amphibians and reptiles. In mammals it has two roles, one at birth to facilitate the change from foetal to adult circulation and secondly to prevent systemic hypoxaemia by ensuring correct ventilation perfusion matching in the presence of lung disease [15]. Excessive HPV such as occurs in high altitude pulmonary oedema is harmful and a counter regulatory mechanism which protects the right heart has been hypothesized by several authors [16].

The cellular events leading to HPV are still poorly understood. The effector mechanism is likely to be a depolarization caused by a closure of an outward potassium channel thus leading to influx of calcium through voltage gated calcium channels. This hypothesis is supported by direct patch clamping studies $[17,18]$ and by the potency of drugs acting at these channels to inhibit HPV [13]. However, the intracellular events which lead to this change in ion flux are still a mystery.

Whilst ANP has been shown to be a vasodilator of the pulmonary vascular bed in vivo and in vitro, we felt it important to study the effect of ANP in isolated ves- sels in response to hypoxia particularly since in this system HPV has recently been shown to be characteristically biphasic $[13,14]$. Our results indicate that ANP is a highly effective vasorelaxant of HPV in pulmonary artery resistance vessels with EC50 values within the range that occur in vivo, thus supporting a physiological role. This contrasts with a study performed under identical conditions using $\mathrm{PGF}_{2 \alpha}$-contracted vessels [9]. Here, ANP was much less potent: the EC50 was $62 \mathrm{mM}$ in control and $28 \mathrm{nM}$ in $\mathrm{CH}$ vessels, in comparison to 2.4 and $2.0 \mathrm{nM}$, respectively, when the agonist was hypoxia. The magnitude of the relaxation achieved was also much less: 37 and $63 \%$ of the $\mathrm{PGF}_{2 \alpha}$ contraction in $\mathrm{C}$ and $\mathrm{CH}$ vessels, respectively, in comparison with the virtually complete inhibition and relaxation of hypoxic contractile responses. This apparent selectivity for HPV as a contractile agonist may be linked with the intracellular activity of ANP causing release of cyclic guanosine monophosphate (cGMP) via particulate guanylate cyclase. In pulmonary vascular smooth muscle, cGMP may act directly on a calcium-sensitive potassium channel, decreasing the tendency for membrane depolarization and thus the ability of the cell to react to hypoxia with vasoconstriction [19].

Which of the two phases of HPV seen in isolated vessels represents the true HPV seen in vivo is currently a matter of much debate. The first phase has the right time course of onset, but rapidly diminishes. In this study, the second phase generated much less wall tension, but this was more than adequate to close the vessel lumen. Calculated equivalent intramural pressures of the second phase were $9.0 \mathrm{kPa}(68 \mathrm{mmHg})$ and $9.6 \mathrm{kPa}(72$ $\mathrm{mmHg}$ ) in $\mathrm{C}$ and $\mathrm{CH}$ vessels, respectively [12]. Unfortunately, the response to ANP was not helpful in separating these two phases since it was highly potent against both. It is likely that HPV in vivo represents a summation of both phases in whole lung.

Chronic hypoxia leads to pulmonary hypertension and is known to cause pulmonary vascular remodelling with extension of identifiable muscle distally into previously thin-walled arterioles of diameter less than $80 \mu \mathrm{m}$. We made an effort to consistently select vessels of a similar size, and the diameters of the $\mathrm{C}$ and $\mathrm{CH}$ vessels in both experiments were comparable. The contractility of the vessels from $\mathrm{CH}$ animals both to hypoxia and $\mathrm{KCl}$ was less than that of the vessels from their normoxic littermates. This is likely to be due to morphological changes within the vessel wall secondary to pulmonary vascular remodelling. In the rat, characteristic features are the development of a double elastic lamina and medial hyperplasia. Both phases of hypoxic pulmonary vasoconstriction were demonstrable in normal and remodelled rat pulmonary resistance vessels and were potently inhibited by ANP. The responses of the $\mathrm{C}$ and $\mathrm{CH}$ vessels to ANP were similar. We have previously found that the potency of ANP against HPV was greater in isolated perfused lungs from $\mathrm{CH}$ rats compared to controls [10]. It may be that the neomuscularized vessels, which are rather smaller than those examined in this study, contribute substantially to the pulmonary vascular resistance of $\mathrm{CH}$ animals. Thus, the explanation for the increased potency of ANP in the intact remodelled vascular bed may be the extended site of action available to ANP. 
These findings are further evidence for an important action of atrial natriuretic peptide on the pulmonary circulation, showing for the first time powerful antagonism of both phases of hypoxic contraction of isolated pulmonary resistance vessels, and with no attenuation of the response in remodelled vessels from chronically hypoxic rats.

\section{References}

1. Adnot S, Chabrier PE, Andrivet P, et al. Atrial natriuretic peptide concentrations and pulmonary hemodynamics in patients with pulmonary artery hypertension. Am Rev Respir Dis 1987; 136: 951-956.

2. Burghuber OC, Hartter E, Punzengruber C, Weissel M, Woloszczuk W. Human atrial natriuretic peptide secretion in precapillary pulmonary hypertension. Clinical study in patients with COPD and interstitial fibrosis. Chest 1988; 93: 31-37.

3. Morice AH, Pepke-Zaba J, Brown MJ, Thomas P, Higenbottam TW. Atrial natriuretic peptide in primary pulmonary hypertension. Eur Respir J 1990; 3: 910-913.

4. Rogers TK, Sheedy W, Waterhouse J, Howard P, Morice AH. Haemodynamic effects of atrial natriuretic peptide in hypoxic chronic obstructive pulmonary disease. Tho$\operatorname{rax} 1994$; 49: 233-239.

5. Jansen TL, Morice AH, Brown MJ. A comparison of the vasodilator responses to atrial peptides in the pulmonary and renal arteries of the pig in vitro. BrJ Pharmacol 1987; 91: 687-691.

6. Cigarini I, Adnot S, Chabrier PE, Viossat I, Braquet P, Gaujour B. Pulmonary vasodilator responses to atrial natriuretic factor and sodium nitroprusside. J Appl Physiol 1989; 67: 2269-2275.

7. Lindberg F, Andersson KE. Vasodilator responses to alpha-human-atrial natriuretic peptide in isolated omental and pulmonary arteries from rabbit and man. Acta Physiol Scand 1988; 134: 391-397.

8. Numan NA, Gillespie MN, Altiere RJ. Pulmonary vasorelaxant activity of atrial peptides. Pulm Pharmacol 1990; 3: 29-33.

9. Rogers TK, Stewart AG, Morice AH. Effect of chronic hypoxia on rat pulmonary resistance vessels: vasodila- tation by atrial natriuretic peptide. Clin Sci 1992; 83: 723-729.

10. Stewart AG, Thompson JS, Rogers TK, Morice AH. Atrial natriuretic peptide-induced relaxation of pre-constricted isolated rat perfused lungs: a comparison in control and hypoxia-adapted animals. Clin Sci 1991; 81: 201-208.

11. Adnot S, Chabrier PE, Brun-Buisson C, Viossat I, Braquet $\mathrm{P}$. Atrial natriuretic factor attenuates the pulmonary pressor response to hypoxia. J Appl Physiol 1988; 65: 19751983.

12. Raffestin B, Levame M, Eddahibi S, et al. Pulmonary vasodilatory action of endogenous atrial natriuretic factor in rats with hypoxic pulmonary hypertension. Effects of monoclonal atrial natriuretic factor antibody. Circ Res 1992; 70: 184-192.

13. Woodmansey PA, Zhang F, Channer KS, Morice AH. Effect of the calcium antagonist amlodipine on the two phases of hypoxic pulmonary vasoconstriction in rat large and small isolated pulmonary arteries. J Cardiovasc Pharmacol 1995; 25: 324-329.

14. Leach RM, Robertson TP, Twort CHC, Ward JPT. Hypoxic vasoconstriction in rat pulmonary and mesenteric arteries. Am J Physiol Lung Cell Mol Physiol 1994; 266: L223-L231.

15. Weir EK, Archer SL. The mechanism of hypoxic pulmonary vasoconstriction: the tail of two channels. Biogenisis 1995; 9: 183-189.

16. Ou LC, Yen S, Sardella GL, Hill NS. Does atrial natriuretic factor protect against right ventricular overload? II. Tissue binding. J Appl Physiol 1989; 67: 1612-1616.

17. Post JM, Hume JR, Archer SL, Weir EK. Direct role for potassium channel inhibition in hypoxic pulmonary vasoconstriction. Am J Physiol 1992; 262: C882C890.

18. Yuan XJ, Goldman W, Tod M, Rubin L, Blaustein M. Hypoxia reduces potassium currents in cultured rat pulmonary but not mesenteric arterial myocytes. Am J Physiol 1993; 264: L116-L123.

19. Archer S, Huang J, Hampl V, Nelson D, Shultz P, Weir EK. Nitric oxide and cGMP cause vasodilation by activation of a charybdotoxin sensitive $\mathrm{K}$ channel by a cGMP dependent protein kinase. Proc Natl Acad Sci USA 1994; 91: 7583-7587. 